\title{
Immigration, Education and Wage Inequality
}

\author{
Christian Lumpe \\ Justus-Liebig-University Gießen \\ Benjamin Weigert \\ Justus-Liebig-University Gießen
}

\begin{abstract}
In this paper we analyse the effect of immigration on the labour market prospects of different skill groups among natives. We develop a model of endogenous labour supply in which immigration affects educational decisions of natives. We argue that the distributional consequences of immigration with respect to between-skill group inequality are ambiguous in general and crucially depend on the host country's level of educational attainment. We show that this result is robust irrespective of labour market institutions as e.g., with a rigid wage regime featuring unemployment. Additionally, the model is applied to assess the impact on within-skill group wage inequality.
\end{abstract}

- JEL Classification: F22, J31

- Key Words: Human-capital Investment, Immigration, Wage Inequality, Heterogeneity, Labour Market

\section{Introduction}

Large and steady inflows of (il)legal immigrants into the US and Western Europe are a striking fact of the last five decades. While the workforce of those

\footnotetext{
*Corresponding address: Christian Lumpe; Justus-Liebig-University Gießen, Department of Economics, D-35394 Gießen, Germany; e-mail: christian.lumpe@wirtschaft.uni-giessen.de. Opinions expressed in this paper are those of the authors and do not necessarily reflect views of the German Council of Economic Experts /Benjamin Weigert; German Council of Economic Experts; Scientific Staff, GustavStresemann-Ring 11, D-65180 Wiesbaden, Germany; e-mail: benjamin.weigert@destatis.de/ benjamin.weigert@wirtschaft.uni-giessen.de.

๑2010-Center for International Economics, Sejong Institution, Sejong University, All Rights Reserved.
} 
countries is considered to be relatively high-skilled, a large share of their immigration today is considered to be low-skilled. ${ }^{1}$ Much of the public and academic discussion revolves around the potential and actual impact of this mostly low-skilled immigration on the host countries' labour market. One of the most hotly debated topics both in the public and among scholars is the impact of immigration on labour market prospects of native workers. From a welfare perspective low-skilled immigration is beneficial for the host country as long as labour markets are competitive, although there may arise unintended distributional effects. However, when labour markets are not fully competitive - a characterisation that may apply to many Continental European countries - the effects of immigration of low-skilled workers will depend on labour market institutions. ${ }^{2}$ In both settings it is shown, that the wage of low-skilled workers has to fall.

In this paper we extend the existing theoretical literature on the distributional aspects of low-skilled immigration by introducing heterogeneous agents who decide on their level of educational attainment. We show that (i) the impact of lowskilled immigration on between-skill group wage inequality is ambiguous in general and the sign of the measured wage impact depends strongly on the level of educational attainment at the time of immigration. (ii) Residual wage inequality in the latest cohort of native high-skilled workers is likely to increase with low-skilled immigration while existing cohorts with given educational levels will only be slightly affected. ${ }^{3}$ (iii) In a rigid wage regime defined either implicitly via social security systems or explicitly via binding minimum wages - as found e.g., in most Continental European countries - the labour market and inequality measures will be affected in quite the same way as in competitive labour markets (as stated in (i) and (ii)). Even though, those effects will be quantitatively smaller at the cost of increased unemployment.

In most of the theoretical literature, immigration is modeled by assuming fixed labour endowments and competitive labour markets in the host country (for a brief summary of this literature cf. Borjas, 1995). Within this framework the

\footnotetext{
${ }^{1}$ See Card (2009) for a recent summary on legal immigration; Espenshade (1995) and Passel (2005) on illegal immigration.

${ }^{2}$ In a theoretical model with fixed supply of heterogeneous labour, Kemnitz (2009) shows that even highskilled immigration may lead to an aggregated welfare loss of natives if redistribution resulting from high-skilled to low-skilled workers via the unemployment insurance scheme is actuarially not too unfair. ${ }^{3}$ For a detailed discussion on residual wage inequality in the context of immigration see Card (2009); a much broader discussion of the evolution on US wage inequality can be found in e.g., Lemieux (2006).
} 
assumptions on capital mobility solely determine which kind of immigration is optimal for the host country. Nevertheless it is shown that immigration is never detrimental and therefore there exists an immigration surplus for the native population. However, it is shown that immigration results in a wage effect thereby influencing wage inequality in the host country. Within the competitive labour market framework, Chiswick (1989) emphasises that immigration and its induced change in relative wages directly influences educational decisions of natives. Chiswick (1989) discusses the interdependency between the educational level and the respective quantity of immigrants as well as the human-capital investment decision of natives - however without discussing their implications for the wage distribution and observed inequality. There are plenty of studies concerning the wage effect that obtain a rather large negative wage effect, a small but insignificant wage effect or even a positive wage effect. ${ }^{4}$ These classical results will not fully apply when the assumption of an undistorted labour market is removed. Schmidt et al. (1994) show that both - higher native unemployment or increased employment might arise depending on substitutability or complementarities of low-skilled and high-skilled workers. Most important, immigration of low-skilled workers may act as a disciplining tool inducing unions to lower their wage claim. Within an efficient bargaining model, Fuest and Thum (2001) endogenise labour supply but abstracting from any heterogeneity. It is shown that the reaction of the labour supply to the expected future immigration internalises the negative effect of immigration on the labour market outcome of workers. Since their results depend on the incorporated bargaining process, our results are different concerning unemployment and the evolution of wage dispersion.

We introduce a general equilibrium model with heterogeneous individuals who decide on education and thereby forming the aggregate labour supply of lowskilled and high-skilled workers. ${ }^{5}$ Heterogeneity is introduced by an ability distribution. The wage inequality between skill groups - measured by the ratio of median (or mean) income between the educational groups - depends on the relative wage and on the ability composition of both groups. Hence, the influence of immigration on the labour market is twofold: First, by changing the relative wage, immigration has an effect on the skill premium. We call this channel the wage effect of immigration. Second, a changing relative wage will induce natives to

\footnotetext{
${ }^{4}$ See Okkerse (2008) for a broad overview.

${ }^{5}$ The model extends the basic approach elaborated by Meckl and Zink (2002). In contrast to Chiswick (1989) we endogenise the educational decision of heterogeneous workers.
} 
revise their educational decisions. This will modify the ability composition of the respective educational groups and constitutes what we call the compositional effect of immigration. We show that immigration of low-skilled labour magnifies the aforementioned wage effect if the level of education is sufficiently high in the host country. However, with a lower level of education this wage effect is likely to be compensated. Thus, with endogenous educational decisions the host countries' educational attainment is an important factor explaining the impact of immigration on the between-group wage inequality. Additionally, we show that low-skilled immigration increases residual or within-group wage inequality among the latest cohort of high-skilled natives as their composition is directly influenced by educational decisions. The basic mechanism of magnification or compensation remains valid even when accounting for rigidity of wages. In this economic environment the change of wage inequality between skill groups is accompanied by an increase of the unemployment of low-skilled workers.

The remainder of the paper is organised as follows. In Section II, we present the basic model, discuss the labour market equilibrium, our measure of skill premium and immigration and its influence on the economy. Section III discuss the results and concludes.

\section{The Model}

We consider an economy in which competitive firms produce a single homogeneous consumption good $Y$ using two different factors of production: highskilled labour $H$ and low-skilled labour $L$ each measured in efficiency units. The production technology $Y(H, L)$ is assumed to satisfy the following requirements: (i) $\partial Y / \partial i>0$ and $\partial^{2} Y / \partial i^{2}<0$, (ii) $\lim _{\mathrm{i} \rightarrow 0} \partial Y / \partial i=\infty \lim _{\mathrm{i} \rightarrow \infty} \partial Y / \partial i=0$ for $i=H, L$ (iii) $\gamma Y=Y(\gamma H, \gamma L)$. Normalising the price of the final product to one, profit maximisation of firms leads to the following first order conditions:

$$
\partial Y / \partial H=w_{H}, \quad \partial Y / \partial L=w_{L}
$$

The first order conditions in (1) define the aggregate relative labour demand of high-skilled to low-skilled efficiency units $g(\omega)$ as a function of the relative factor price $\omega \equiv w_{H} / w_{L}$. Given our assumption of the production technology it follows that $g^{\prime}(\omega)<0$. 


\section{A. Households}

Individuals are assumed to be heterogeneous with respect to their abilities $a .^{6}$ Abilities are continuously distributed on the support $[0,1]$ according to a general density function $f(a)$. The total native population is normalised to mass one.

Given his ability $a$, an agent has to decide whether he invests in education or not. Without any further education he supplies $(1+a)$ efficiency units of low-skilled labour and earns a total wage income of $W_{L}(a)=(1+a) w_{L}$. Alternatively he can spend an exogenously given fraction of time $\lambda$ on further education to supply $(1+b a)(1-\lambda)$ efficiency units of high-skilled labour. ${ }^{7}$ The parameter $b>1$ measures the gross effect of education on marginal efficiency units of a trained worker with ability $a$. Hence, a trained worker earns a total wage income of $W_{H}(a)=(1+b a)(1-$ $\lambda) w_{H}$. We assume that both types of labour are qualitatively different: a low-skilled worker cannot work as high-skilled worker and vice versa. ${ }^{8}$

Preferences are defined over the consumption of the homogeneous good $Y$ and are identical for all workers. Thus, an agent maximises his total wage income and chooses to invest in training if his ability is higher than some threshold value $t$ defined by:

$$
(1+b t)(1-\lambda) w_{H}=(1+t) w_{L}
$$

Workers with ability $t$ are indifferent between investing in education or not. The threshold value depends on the relative factor price $\omega$ and on the exogenous parameters $b$ and $\lambda$. Graphically the threshold is given by the intersection of the two wage functions and can be calculated as:

$$
t=\frac{(1-\lambda) \omega-1}{1-b(1-\lambda) \omega}
$$

\footnotetext{
${ }^{6} \mathrm{We}$ interpret abilities as a mixture of innate abilities and knowledge acquired during compulsory schooling. The educational choice modeled in our paper is therefore a choice of further education.

${ }^{7}$ The model can be reformulated as an explicit dynamic model by applying an OLG framework of the following structure: In the first period an individual would either acquire education and work for the remaining time $(1-\zeta)$ as high-skilled worker or start working immediately as a low-skilled worker. In the second period, both households would work and consume their lifetime income. Abstracting from discounting (or assuming an interest rate of 0 ) this is formally equivalent to $\lambda=\zeta / 2$.

${ }^{8} \mathrm{We}$ consider the time to educate as some kind of institutional parameter set by the curriculum of the respective institutions as, e.g., colleges and universities. Alternatively, one could model the educational decision in a more elaborated way by relating the achievable stock of human capital to the necessary time to educate and by letting individuals choose the optimal time to educate and finally whether or not to educate at all. The basic qualitative results of our model however would be the same.
} 
The parameters $b, \lambda$ and the relative wage $\omega$ have to satisfy the following condition: $2 /(1+b) \leq(1-\lambda) \omega \leq 1$, such that $t$ lies in the interval $[0,1]$. For the remainder of the paper we assume that this condition is fulfilled. If the relative wage changes, the threshold value changes according to:

$$
t^{\prime}(\omega)=\frac{(1-\lambda)(1+b t)}{1-b(1-\lambda) \omega}<0
$$

A higher relative wage makes it favourable for agents with lower ability to invest in training. Even a small change in $\omega$ might result in a large reaction of $t$ if the denominator is close to zero.

The economy's total supply of low-skilled labour and high-skilled labour corresponds to the weighted sum of efficiency units of the respective group and therefore depends directly on the training decisions made by households:

$$
L(\omega)=\int_{0}^{t(\omega)}(1+a) f(a) d a, \quad H(\omega)=\int_{t(\omega)}^{1}(1-\lambda)(1+b a) f(a) d a
$$

Obviously $L^{\prime}(\omega)<0$ and $H^{\prime}(\omega)>0$ since a higher relative wage decreases the threshold value of education thereby expanding the ability interval of the highskilled workers while simultaneously narrowing that of the low-skilled workers. Consequently, relative labour supply $h(\omega) \equiv H(\omega) / L(\omega)$ can be written as a function of the relative wage $\omega$. Given the properties of the respective labour supply functions the relative labour supply is positively sloped: $h^{\prime}(\omega)>0$ and depends on the structural parameters $b$ and $\lambda$.

\section{B. A Measure of Wage Inequality between Skill Groups}

The properties of the relative labour supply and the relative labour demand guarantee a unique labour market equilibrium $\left\{\omega^{*},(H / L)^{*}\right\}$ in terms of efficiency units. $^{9}$

In order to discuss the influence of immigration on the wage distribution of the different skill groups, we have to define an appropriate wage measure. An apparent measure for the wage of the respective group is the median wage. ${ }^{10}$ We define natives' measure of wage inequality between skill groups $x$ - the measured skill

\footnotetext{
${ }^{9}$ Throughout the paper asterisks denote equilibrium values.

${ }^{10}$ The mean wage as wage measure can also be addressed without changing the results of the model qualitatively. The ratio of the median wage as a measure of premia of different skill groups has been used extensively in empirical research (cf. Greiner et al., 2004).
} 
premium - as the ratio of the representative wage of high and low-skilled workers $m_{H}$ and $m_{L}$ :

$$
x=\frac{m_{H}(t)}{m_{L}(t)}=\frac{m(w \mid a \geq t)}{m(w \mid a<t)}=\omega \frac{(1+b m(a \mid a \geq t))(1-\lambda)}{1+m(a \mid a<t)}
$$

The measured skill premium is the product of two terms: The first term is the relative wage while the second term is the ratio of median (or representative) efficiency units of high-skilled and low-skilled labour. A change of the equilibrium relative wage $\omega$ resulting from immigration will change the skill premium directly via the first term. Besides this wage change, a change of the relative wage $\omega$ also changes the incentives to educate and thus the ratio of median efficiency units supplied by each skill group. We call the resulting change of the different skill groups the compositional effect. To measure any change in the skill premium resulting from a change in the relative wage, we compute the elasticity of the skill premium $\varepsilon_{x, \omega}$ with respect to the relative wage:

$$
\begin{aligned}
& \varepsilon_{x, \omega}= x^{\prime}\left(\omega^{*}\right) \frac{\omega^{*}}{x\left(\omega^{*}\right)}=1-\left|t^{\prime}\left(\omega^{*}\right)\right| \omega^{*} G\left(t^{*}\right), \\
& \text { with } G(t)=\left(\frac{b m_{H}^{\prime}(t)}{1+b m_{H}(t)}-\frac{m_{L}^{\prime}(t)}{1+m_{L}(t)}\right)
\end{aligned}
$$

The first term in equation (7) - the one - represents the wage effect. The compositional effect $\left(\left|t^{\prime}\left(\omega^{*}\right)\right| \omega^{*} G\left(t^{*}\right)\right)$ measures the change in the composition of the different skill groups due to changing educational decisions. The sign of the compositional effect crucially depends on the function $G(t)$ which measures the difference in the rate of change of the representative efficiency units in the two skill groups. The sign of the function $G(t)$ is ambiguous meaning that the aggregated effect of immigration on the measured skill premium is ambiguous as well. The initial relative wage change will be magnified by a change in the ability composition of the different skill groups if $G(t)<0$ holds. In the case of $G(t)>0$, the resulting change in the skill groups' ability composition will compensate the initial change in relative wage. Whether magnification or compensation of the initial change of the relative wage will be observed crucially depends on the initial relative labour supply and on the distribution of abilities $f(a)$.

\section{Immigration in Competitive Labour Markets}

Immigration is modelled as an inflow of efficiency units of labour denoted by 
$H_{I}$ and $L_{I}$. To keep matters simple, we assume that immigrants are not allowed to invest in education in the host country. ${ }^{11}$ Any kind of relative immigration $H_{I} / L_{I}$ that differs from the pre-immigration equilibrium relative supply will change the relative wage in the host country. The equilibrium relative wage rate increases (decreases) if the immigration includes relatively less (more) high-skilled efficiency units compared to the existing equilibrium relative labour supply in the host country. For the remainder of the paper we limit the discussion to the case of relatively low-skilled immigration. We analyse the percentage change of the measured skill premium (6) to determine the distributional consequences of immigration. As indicated above the change of the skill premium can be decomposed into a wage effect and into a compositional effect. Thus, the net impact of low-skilled immigration on the wage distribution is not as clear cut as it might seem at first sight. It crucially depends on the educational level in the host economy.

Assumption 1. Abilities are distributed according to a symmetric and unimodal distribution with median and mean equal to $1 / 2$. The following boundary conditions are also imposed:

$$
f(0)=f(1)=c \geq 0 \text { and } \lim _{a \rightarrow 0} f^{\prime}(a)=-\lim _{a \rightarrow 1} f^{\prime}(a)>0
$$

We will proceed as follows: First, we calculate the compositional effect $G(t)$ for our measure of the representative wage and show under which conditions the direct wage effect is magnified or compensated. Second, we discuss the difference between both measures and illustrate our findings.

The median ability of the low-skilled workers $a_{L}(t)$ and the high-skilled workers $a_{H}(t)$ are defined by: ${ }^{12}$

$$
a_{L}(t) \equiv F^{-1}\left[\frac{F(t)}{2}\right], a_{H}(t) \equiv F^{-1}\left[\frac{1-F(t)}{2}\right]
$$

\footnotetext{
${ }^{11}$ The assumption concerns the overwhelming part of e.g., the immigration to the U.S. These immigrants are low-skilled ( $40 \%$ are high-school drop-outs) and are immigrating to find jobs in the Western World. In this context it is also important whether or not the second generation (immigrants' offspring) is still considered as immigrants. However, analysing second generations' educational decision is of high importance in its own right (cf. Card, 2005).

${ }^{12}$ The median for the respective groups is calculated using the conditional ability distribution: $[1 / F(t)] \int_{0}^{t} f(a) d a$ and $[1 /(1-F(t))] \int_{t}^{1} f(a) d a$.
} 
Considering the derived formula for $G(t)$ in (7), we need to compute the change of the median abilities due to a change in the threshold value $t$ :

$$
\frac{d a_{L}(t)}{d t}=\frac{1}{2} \frac{f(t)}{f\left(a_{L}(t)\right)}, \frac{d a_{H}(t)}{d t}=\frac{1}{2} \frac{f(t)}{f\left(a_{H}(t)\right)}
$$

Using those derived formulas above in the definition of $G(t)$ (equ. (7)) gives us the condition for magnification:

$$
G(t)=\frac{1}{2}\left[\frac{f(t)}{f\left(a_{H}(t)\right)} \frac{b}{1+b a_{H}(t)}-\frac{f(t)}{f\left(a_{L}(t)\right)} \frac{1}{1+a_{L}(t)}\right]<0
$$

and we arrive at the following proposition:

Proposition 1. Under assumption 1 and the additional requirement that $f(0)=f(1)=c, c \in[0,1 / 2]$, the effect of a change in the relative wage on the skill premium - measured by median wages - through immigration is magnified (compensated) by an endogenous labour-supply reaction, iff the relative labour supply before immigration is sufficiently high (low).

Proof. Please consult the appendix.

The requirement $f(0)=f(1)=c \in[0,1 / 2]$ is not very restrictive because even a boundary weight of $1 / 2$ is rather implausible. Especially, if one thinks of abilities as some kind of measurable IQ the usual distribution used in IQ studies is the normal distribution with a mean of 100 and a standard deviation of 10 to 15 . Applied to our chosen standardisation of abilities between zero and one this would give us an approximate weight of zero for the lower and upper bound of the ability interval.

Figure 1 illustrates the cases for magnification and compensation applying a triangle distribution. The function $G(t)$ is calculated by using both mean and median wages of the respective skill groups. As illustrated by this figure, there is no qualitative difference in using the median or the mean wage as the representative wage. In both cases magnification is likely to occur the higher the educational attainment - proxied by a low threshold value $t$ - while compensation needs a rather low educational attainment in the host country. Thus, the impact of low-skilled immigration on between-skill group wage inequality is therefore rather ambiguous and depends largely on the existing labour supply or educational attainment: Between-group inequality - measured by some ratio of average or mean wages - is likely to rise if educational attainment is high while it is likely to decrease if educational attainment is low. 
Figure 1. Flexible Wage Case - Compensation/Magnification and Educational Attainment

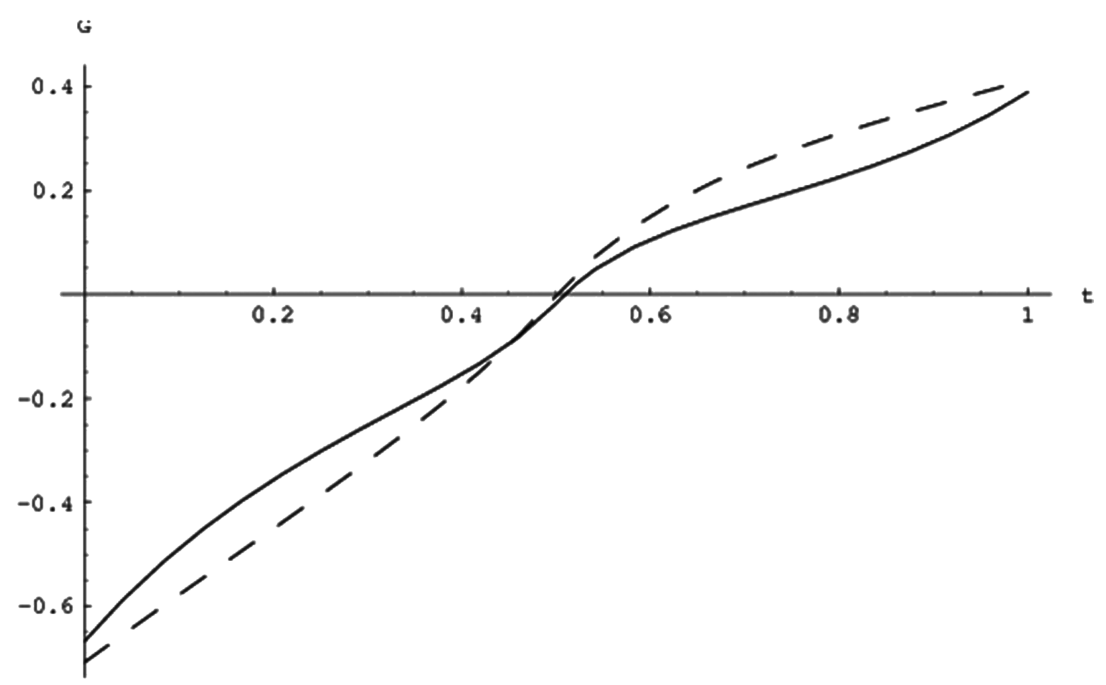

Notes: The function $G(t)$ assuming a triangle distribution and $b=1.4$. The dashed line depicts the median and the solid line depicts the mean.

The model can well be formulated as a dynamic model with various cohorts of workers who already took their educational decision (cf. footnote 7). If low-skilled immigration is permanent - in the sense that each period low-skilled immigrants enter the country and their offspring are considered as natives - then the equilibrium in our model resembles qualitatively the steady state of a dynamic model. If we assume that only a small share of already educated individuals will revise their educational decision in later stages of their working life, e.g., by taking up a study, their relative labour supply will be rather inelastic. ${ }^{13}$ As a consequence, most of the educational adjustment to changing relative wages resulting from lowskilled immigration will in fact take place in the latest (youngest) cohort of workers. The latest cohort will therefore show both effects described by our model - the wage and the compositional effect that results from changing patterns of educational attainment. In case of native educational attainment being compatible with magnification, low-skilled immigration will therefore increase even more the measured wage inequality between skill groups in the latest cohort. A second result is that we will observe a strong increase of residual wage inequality for highskilled workers of the latest cohort as both their wage increases and their ability

${ }^{13}$ Of course, the longer a worker's remaining working life, the more profitable would be a change of his occupation if relative wages change. 
distribution widens due to higher educational attainment in this group (the threshold $t$ decreases thereby widening the ability interval). ${ }^{14}$ In the long run, all cohorts will show the same steady state level of educational attainment such that the observed aggregated (over all cohorts) within- and between-group wage inequality will increase compared to the pre-immigration steady state. In the case of temporary low-skilled immigration (with immigrants' offspring considered as natives), rational agents will anticipate that relative wage changes are only temporary. Consequently the transitory adjustment of educational decisions will be quantitatively smaller and return to their steady state educational attainment. Therefore, the distributional effects described by our model would be transitory as well.

\section{Immigration and Rigid Wages}

In this subsection we analyse the influence of immigration on the measured skill premium with a minimum wage. Binding minimum wages either set implicitly via a system of social security institutions or explicitly via minimum wages set by the government or some other institutions are found in many countries of Continental Europe. Therefore, it is important to extend the model to assess the impact of lowskilled immigration on labour market prospects of various skill groups in countries characterised by such institutions. Consider a real minimum income $\bar{w}$ per physical unit of labour, which is binding only for the group of low-skilled workers. ${ }^{15}$ Then there exists an ability threshold $\bar{a}\left(w_{L} ; \bar{w}\right)$ representing the least employable ability:

$$
\bar{a}\left(w_{L} ; \bar{w}\right)=\left\{a: \bar{w}=(1+a) w_{L}, \bar{w}>w_{L}\right\}
$$

Any worker with abilities lower than $\bar{a}\left(w_{L} ; \bar{w}\right)$ will not be employed by firms because the minimum wage income is larger than the marginal productivity of the worker. The native unemployment rate resulting from such a binding minimum wage

\footnotetext{
${ }^{14}$ Lemieux (2006) highlights the importance of the compositional effect - measured as a change in the skill and experience distribution - on the measured residual wage inequality. To simplify matters we ignored experience. A model accounting for experience would provide an even richer dynamics of between-skill group as well as residual wage inequality.

${ }^{15}$ Two different scenarios are possible: a binding minimum wage before and after immigration or an initially non-binding minimum wage which then becomes a binding one after immigration of lowskilled labour. We analyse only the first scenario since the second is just the transition from the flexible wage case to that of a binding minimum wage case.
} 
is given by all workers with abilities lower than the threshold value $\bar{a}\left(w_{L} ; \bar{w}\right)$ :

$$
U\left(w_{L} ; \bar{w}\right)=\int_{0}^{\bar{a}\left(w_{L} ; \bar{w}\right)} f(a) d a
$$

A lower wage rate in efficiency units for low-skilled workers drives the ability threshold $\bar{a}$ up and leaves more low-skilled workers unemployed: $\overline{d a} / d w_{L}<0$.

With minimum wage legislation we have to differentiate between the relative labour supply and the employable relative labour. The relative labour supply results from educational decisions of individuals at a given relative wage $\omega$. However, a binding minimum wage leaves all workers $a<\bar{a}$ unemployed. This leads to higher employable relative labour with a binding minimum wage. Both, relative labour supply and the employable labour supply coincide in the case of a non-binding minimum wage. Given our assumptions about the technology, the low-skilled wage rate is a function of the relative labour used in production. Therefore we can define $\eta$ as the specific relative efficiency units of labour used in production leading to a wage rate of low-skilled workers $w_{L}$ which equals the minimum wage:

$$
\eta=\left\{\frac{H}{L}: \frac{\partial Y}{\partial L}=\bar{w}\right\}
$$

We define the employable relative labour including the supply of immigrants of both skill groups as:

$$
H / L= \begin{cases}h_{I}(\omega) & h_{I}(\omega) \geq \eta \\ \frac{H_{I}+H(\omega)}{L_{I}+L(\omega)-U\left(w_{L} ; \bar{w}\right)} & h_{I}(\omega)<\eta\end{cases}
$$

A wage rate $w_{L}$ higher than the minimum wage does not change the relative labour supply in comparison to the flexible wage case. Whenever the wage rate for low-skilled labour is smaller than the minimum wage $w_{L}<\bar{w}$, unemployment increases the employable relative labour supply as represented by the second term. With a binding minimum wage the equilibrium relative wage rate will be lower compared to the flexible wage case because the employed relative labour is higher. Compared to a country with flexible wages, we observe less education but higher relative employment of high-skilled labour.

When it comes to our measure of the skill premium the wage of the high-skilled group is the same as in the flexible wage case. But with a binding minimum wage 
we have to revise the representative wage of the low-skilled group because a part of the low-skilled workers are unemployed and without any wage income:

$$
m_{L}=m(w \mid \bar{a} \leq a<t)=1+m(a \mid \bar{a} \leq a<t)
$$

Due to the minimum wage, the wage distribution is truncated at $\bar{w}$ leading to a higher representative wage than under flexible wages. If we use the representative wage in equation (11), we end up with the measured skill premium with a binding minimum wage:

$$
x=\frac{1+b m(a \mid a \geq t)}{1+m(a \mid \bar{a} \leq a<t)}(1-\lambda) \omega
$$

Now the measured wage differential by education does not only depend directly on $\omega$ and the educational threshold $t(\omega)$ but also on the minimum wage $\bar{w}$ via the least employable ability $\bar{a}$. Note that there might be significant differences in the skill premium among countries with rigid wages depending on the absolute value of minimum wages. The skill premium under rigid wages can be lower or higher in comparison to the flexible wage case. As the discussion of the change of the skill premium in the flexible wage case has shown the qualitative results are indifferent concerning the use of the median or mean wage. Therefore we limit our discussion of rigid wages to the median wage.

Consider immigration of low-skilled workers $d H_{I} / d L_{I}<(H / L)^{*}$ into a country with a binding minimum wage, where we assume that a part of the lowskilled immigrants have abilities high enough to be employed in the preimmigration economy. ${ }^{16}$ Immigrants directly compete with native low-skilled workers and therefore deteriorate their group's wage position. The wage income of all low-skilled workers declines and $\bar{a}$ increases which pushes even more lowskilled workers into unemployment as their ability is not high enough to guarantee a total income higher than the minimum income. The equilibrium relative wage $\bar{\omega}^{*}$ increases and the relative employment of high-skilled labour falls even though more natives invest into training (originating from a lower threshold value $t$ ). When it comes to the change in the measured skill premium, results differ strongly from the flexible wage case. With binding minimum wages the percentage change of the skill premium resulting from a one percent change of the relative wage can be

${ }^{16}$ If all immigrants have abilities below $\bar{a}$ nothing will change in the host economy because they are not employable workers. 
calculated as:

$$
\begin{gathered}
\varepsilon_{x, \omega}^{R}=1-\left|t^{\prime}\left(\bar{\omega}^{*}\right)\right| \bar{\omega}^{*} G_{R}\left(t^{*}\right)-\bar{\omega}^{*} \frac{1}{1+m_{L}\left(\bar{a}^{*}, t^{*}\right)} \frac{\partial m_{L}\left(\bar{a}^{*}, t^{*}\right)}{\partial \bar{a}} \frac{d \bar{a}}{d w_{L}} \frac{d w_{L}}{d \omega} \\
\text { with } G_{R}(t)=\left(\frac{b}{1+b m_{H}(t)} \frac{\partial m_{H}(t)}{\partial t}-\frac{1}{1+m_{L}(\bar{a}, t)} \frac{\partial m_{L}(\bar{a}, t)}{\partial t}\right)
\end{gathered}
$$

where $R$ denotes the rigid wage regime. In comparison to the flexible wage case, the change in the skill premium with a binding minimum wage is augmented by a third term. This term measures the change of the representative wage of lowskilled workers due to a change in the least employable abilities $\bar{a}$. This term has a positive sign as long as $d w_{L} / d \omega<0$ which is fulfilled given our assumption about the production technology. Therefore the change in the unemployment of low-skilled workers always counteracts the direct wage effect.

To grasp the wage effects of immigration under minimum wage legislation, we will consider two different formulations of a minimum wage: (i) $\bar{w}=\gamma w_{L}$ for some constant $\gamma>1$ and (ii) $\bar{w}=\delta w_{H}$ for some constant $\delta>0$. The first formulation captures the idea that the social security system offers an outside option, which is for some workers more valuable than their wage income. The second specification can be interpreted as a minimum wage negotiated by a labour union. As to some extent a union tries to reduce the wage dispersion across skill groups by increasing the wage of the lower skill groups (cf. Booth, 1995, pp. 179). We use these simplifying assumptions because we are not interested in modelling the union's decision but in the educational decision of natives. ${ }^{17}$ Both specifications represent polar cases. The first case leads to a constant unemployment rate because $\bar{a}$ is independent of any wage measure, while the second case implies an unemployment threshold $\bar{a}$ proportional to the relative wage $\omega$. However, analysing both cases allows us to draw inferences about any intermediate case. Starting with formulation (i) the third term in (13) vanishes because $\frac{d \bar{a}}{d w_{L}}=0$ holds and we arrive at the following proposition:

Proposition 2. Under assumption 1 and a binding minimum wage given by $\bar{w}=\gamma w_{L}$ the impact of immigration on the skill premium is more likely to be compensated than under flexible wages if the educational threshold

\footnotetext{
${ }^{17}$ Fuest and Thum (2001) model the decision problem of the union but neither the educational decision nor unemployment has been explicitly described.
} 
$t \in[\bar{a}, 1-\bar{a}]$.

Proof: Consider the difference

$$
\Delta \equiv G_{R}(t)-G(t)=1 /\left[f\left(m_{L}\right)\left(1+m_{L}\right)\right]-1\left[f\left(m_{L}^{R}\right)\left(1+m_{L}^{R}\right)\right]
$$

where we used the fact that the representative wages of high-skilled workers and its derivatives are the same in both regimes. We only need to show under which circumstances $\Delta>0$ holds. As $m_{L} \leq m_{L}^{R}$, the sign of $\Delta$ depends on the density $f$ evaluated at the respective median positions. Unimodality and symmetry guarantee that $f\left(m_{L}\right) \leq f\left(m_{L}^{R}\right)$ as long as $t \in[\bar{a}, 1-\bar{a}]$.

The claim of proposition 2 is that the chance of compensation increases with the existence of a minimum wage. This confirms the intuition of wage rigidity, which concludes that the change of wage inequality is dampened, compared to flexible wages. However, the basic mechanism of compensation and magnification that was sketched within a flexible wage framework still exists. Figure 2 illustrates the difference between the flexible and the rigid wage regime. Obviously the

Figure 2. Rigid Wage Case - Compensation/Magnification and Educational Attainment

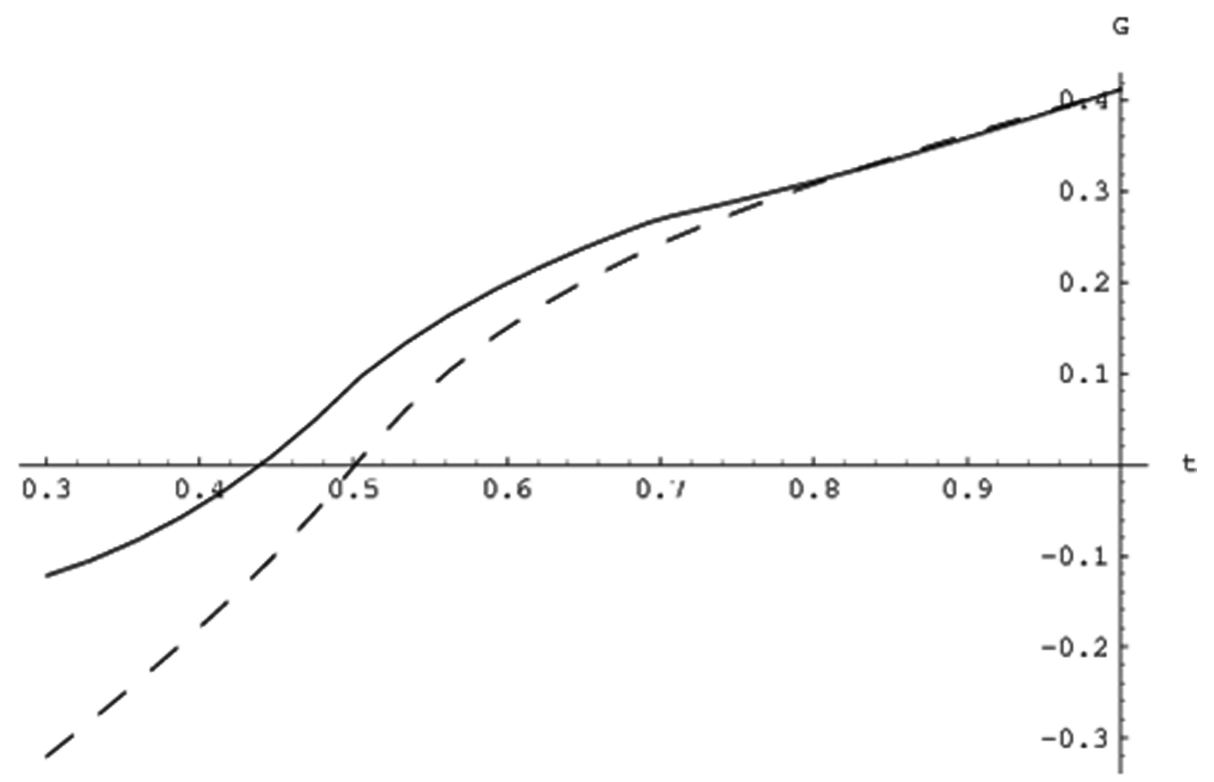

Notes: The function $G(t)$ and $G_{R}(t)$ assuming a triangle distribution and $b=1.4$. The dashed line depicts the flexible wage case and the solid line depicts the minimum wage case assuming a fixed unemployment threshold $\bar{a}=0.3$. 
intersection of $G(t)$ with the $t$ axis moves to the left, leaving a larger interval for magnification. However, the possibility of magnification is still present.

Thus, the main result of our analysis of immigration within the framework of rigid wages is that the mechanism of compensation and magnification is robust. This result differs to the conventional wisdom: under rigid wages we cannot exclude the possibility of magnification of the direct wage effect. More precisely, there is only a higher chance of compensation to arise. Low-skilled immigration into labour market characterised by binding wage rigidities is likely to generate higher unemployment rates and - as our analysis indicates - result in either increasing or decreasing skill premia. Depending on the structural parameters of the economy, low-skilled immigration can therefore lead to an increase of the measured between-skill group wage inequality with flexible and rigid wages alike. The same holds true for the influence on residual wage inequality which will also increase for high-skilled workers with a rather strong increase for the latest cohort due to a change in educational attainment that alters the composition of highskilled workers. However, due to increased unemployment of low-skilled workers the measured residual wage inequality will decline even more compared to the flexible wage case because the ability distribution of employed low-skilled workers shrinks.

\section{Discussion and Conclusion}

We propose an extension of the simple labour market model usually applied in the literature to discuss the labour market impact of low-skilled immigration with special focus on the labour market prospects of native workers. Incorporating endogenous labour supply by modelling educational decisions of agents with inherent heterogeneous abilities we are able to analyse the distributional consequences of low-skilled immigration on native workers of different skill groups. We have shown that low-skilled immigration has an ambiguous influence on the measured wage inequality between skill groups, resulting either in an increase or a decrease in inequality. Furthermore, we show that the existing educational level of the economy before immigration is the main driver of this ambiguity as the change in the ability composition of skill groups can either magnify or compensate the immigration-induced wage change. This can be explained as follows: a high degree of educational attainment leaves a rather small group of low-skilled workers compared to the total workforce. An increase of the 
relative wage - due to low-skilled immigration - adds only a few newly highskilled workers (compared to the existing high-skilled workers) to the lower ends of the high-skilled income distribution. This leads to nearly no change of the average wage income of the high-skilled workers. Compared to the existing small group of low-skilled workers, the drain of those few leads to a significant change of the median wage income of the group of low-skilled workers. Both effects add up to an increase of the between-skill group inequality.

Besides the impact of low-skilled immigration on between-skill group inequality our model allows us to discuss the influence on the residual wage inequality - as discussed e.g., by Card (2009) - and its evolution for various cohorts of workers. We argue that due to the changing educational attainment of workers entering the labour market, residual wage inequality in the latest cohort of native high-skilled workers is likely to increase much stronger with low-skilled immigration compared to existing cohorts where only a small fraction will acquire additional education.

If we extend our model to analyse the impact of low-skilled immigration on labour markets that are characterised by institutions distorting the market mechanism we can show that no principal difference exists with respect to the evolution of between-skill group wage inequality and residual wage inequality. Nevertheless, the change of between-group wage inequality measures is found to be quantitatively smaller but at the cost of increased unemployment.

\section{Acknowledgements}

The authors thank Jürgen Meck1, Stefan Zink and seminar participants in Konstanz, Rome, and Nottingham for helpful comments. Financial support of the Deutsche Forschungsgemeinschaft (DFG, grant FOR 454) is gratefully acknowledged.

Received 18 December 2009, Revised 27 January 2010, Accepted 1 February 2010

\section{References}

Booth, A. L. (1995), The Economics of Trade Union, Cambridge, New York and Melbourne, Cambridge University Press.

Borjas, G. J. (1995), "The Economic Benefits from Immigration”, Journal of Economic Perspectives, Vol. 9, pp. 3-22.

Card, D. (2009), "Richard T. Ely Lecture, Immigration and Inequality", American 
Economic Review, Vol. 99, pp. 1-21.

Card, D. (2005), "Is the New Immigration Really so Bad", The Economic Journal, 115, pp. 300-323.

Chiswick, C. U. (1989), “The Impact of Immigration on the Human Capital of Natives", Journal of Labor Economics, Vol. 7, pp. 464-486.

Espenshade, T. J. (1995), "Unauthorized Immigration to the United States", Annual Review of Sociology, Vol. 21, pp. 195-216.

Fuest, C. and M. Thum (2001), "Immigration and Skill Formation in Unionised Labour Markets", European Journal of Political Economy, pp. 557-573.

Greiner, A., J. Rubart, and W. Semmler (2004), "Economic Growth, Skill-Biased Technical Change and Wage Inequality: A Model and Estimations for the U.S. and Europe", Journal of Macroeconomics, Vol. 26, pp. 597-621.

Kemnitz, A. (2009), "Native Welfare Losses from High Skilled Immigration", International Tax and Public Finance, Vol. 16, pp. 560-570.

Lemieux, T. (2006), "Increasing Residual Wage Inequality: Composition Effects", Noisy Data, or Rising Demand for Skill?”' American Economic Review, Vol. 96, pp. 461-461.

Meckl, J. and S. Zink (2002), "Human-Capital Investment and the Wage Gap", Economic Theory, Vol. 19, pp. 853-859.

Okkerse, L. (2008), "How to Measure Labour Market Effects of Immigration: A Review", Journal of Economic Surveys, Vol. 22, pp. 1-30.

Passel, J. S. (2005), "Estimates of the Size and Characteristics of theUndocumented Population", Research Report of the Pew Hispanic Center, Washington, D.C..

Schmidt, C. M., A. Stilz, and K. F. Zimmermann (1994), "Mass Migration, Unions, and Government Intervention”, Journal of Public Economics, pp. 185-201.

\section{Appendix}

\section{A. Proof of Proposition 1}

First, we proof that the limit of the function $G(t)$ at the lower (upper) bound is always negative (positive): $\lim _{\mathrm{t} \rightarrow 0} G(t)<0, \lim _{\mathrm{t} \rightarrow 1} G(\mathrm{t})>0$. Then we show that $G(t)$ has at most one root. Taking the limit of $G(t)$ at the lower and upper bound of the ability interval gives the following expressions:

$$
\begin{aligned}
& \lim _{t \rightarrow 0} G(t)=\frac{1}{2}\left(\frac{f(0)}{f\left(a_{H}(0)\right)} \frac{b}{1+b a_{H}(0)}-\frac{f(0)}{f\left(a_{L}(0)\right)} \frac{1}{1+a_{L}(0)}\right)=\frac{1}{2}\left(\frac{c}{f(1 / 2)} \frac{b}{1+b / 2}-1\right) \\
& \lim _{t \rightarrow 1} G(t)=\frac{1}{2}\left(\frac{f(1)}{f\left(a_{H}(1)\right)} \frac{b}{1+b a_{H}(1)}-\frac{f(1)}{f\left(a_{L}(1)\right)} \frac{1}{1+a_{L}(1)}\right)=\frac{1}{2}\left(\frac{b}{1+b}-\frac{c}{f(1 / 2)} \frac{2}{3}\right)
\end{aligned}
$$

Because $f(1 / 2)>1$, the term $c / f(1 / 2) \in[0, c)$ and therefore $c<1 / 2$ is a necessary 
and sufficient condition for $\lim _{t \rightarrow 0} G(t)<0$ and $\lim _{t \rightarrow 1} G(t)>0$ to hold independent of the value of $b$. Note that a $b \ll \infty$ also allows for $c>1 / 2$. To get the unambiguous result, that only magnification occurs with relative labour sufficiently high ( $t$ small), we need to rule out more than one root. We define the root of $G(0)$ as the value $t^{*}$ leading to: $G\left(t^{*}\right)=0$. Simplifying the function of $G(t)$ leads to:

$$
\tilde{G}(t)=\frac{f\left(a_{L}(t)\right)}{f\left(a_{H}(t)\right)}-\frac{1+b a_{H}(t)}{b\left(1+a_{L}(t)\right)}
$$

The sign of $G(t)$ and $\tilde{G}(t)$ are the same, therefore it is sufficient to show that $\tilde{G}(t)$ has at most one root because this result will also apply to $\tilde{G}(t)$. Taking the derivative of $\tilde{G}(t)$ gives us:

$$
\tilde{G}(\mathrm{t})=\frac{d f\left(a_{L}(t)\right) / f\left(a_{H}(t)\right)}{d t}-\frac{d\left(1+b a_{H}(t)\right) / b\left(1+a_{L}(t)\right)}{d t}
$$

The first term in (16) is positive because we assumed single peakness and symmetry of the distribution. The second term can be further calculated as:

$$
\frac{d\left(1+b a_{H}(t)\right) / b\left(1+a_{L}(t)\right)}{d t}=\frac{f(t)}{2\left(1+a_{L}(t)\right) f\left(\left(a_{L}(t)\right)\right.}\left(\frac{f\left(a_{L}(t)\right)}{f\left(\left(a_{H}(t)\right)\right.}-\frac{1+b a_{H}(t)}{b\left(1+a_{L}(t)\right)}\right),
$$

implying that the sign of the second term in (16) is given by:

$$
\operatorname{sgn}\left(\frac{d\left(1+b a_{H}(t)\right) / b\left(1+a_{L}(t)\right)}{d t}\right)=\operatorname{sgn}(\tilde{G}(t))
$$

As a consequence we get that whenever $\tilde{G}(t) \leq 0$ holds, we know that $\tilde{G}^{\prime}(t)>0$ and therefore the function $\tilde{G}(t)-$ and also $G(t)-$ can have at most one root. Together with the result of $\lim _{\mathrm{t} \rightarrow 0} G(t)<0$ and $\lim _{\mathrm{t} \rightarrow 1} G(t)>0$, we establish the result that $G(t)$ has one unique root. Furthermore we have proofed for $t$ sufficiently low that magnification occurs $(G(t)<0)$.

\section{B. Comparative Statics of the Labour Market}

Labour market equilibrium $\left(\omega^{*},(H / L)^{*}\right)$ with immigration is given by:

$$
\left(\frac{H}{L}\right)_{L D}=g\left(\omega^{*}\right)
$$




$$
\begin{gathered}
\left(\frac{H}{L}\right)_{L S}=\frac{H_{I}+(1-\lambda) \int_{t\left(\omega^{*}\right)}^{1}(1+b a) f(a) d a}{L_{I}+\int_{\bar{a}\left(w_{L} ; \bar{w}\right)}^{t\left(\omega^{*}\right)}(1+a) f(a) d a} \equiv h_{1}\left(\omega^{*}\right) \\
\bar{a}\left(w_{L}^{*} ; \bar{w}\right)= \begin{cases}\frac{\bar{w}-w_{L}^{*}}{w_{L}^{*}} & \text { if } \bar{w}>w_{L}^{*} \\
0 & \text { otherwise }\end{cases} \\
w_{L}^{*}=f\left((H / L)^{*}\right)-f^{\prime}\left((H / L)^{*}\right)(H / L)^{*}
\end{gathered}
$$

in which the first and second equation constitute the labour supply and demand which are equal in equilibrium $(H / L)_{L D}=(H / L)_{L S}$. The third and the fourth equation give the lowest employable ability at the given minimum wage $\bar{w}$ and the resulting low-skilled wage per efficiency units at the equilibrium ratio of high to low-skilled labour. Since we are interested in the equilibrium change of the relative wage and of the relative physical labour supply through immigration, we take the total differential of labour demand and supply:

$$
\begin{gathered}
d\left(\frac{H}{L}\right)_{L D}^{*}=g^{\prime}\left(\omega^{*}\right) d \omega^{*} \\
d\left(\frac{H}{L}\right)_{L S}^{*}=\frac{\partial(H / L)_{L S}}{\partial \omega} d \omega^{*}+\frac{\partial(H / L)_{L S}}{\partial \bar{a}} \frac{d \bar{a}}{d w_{L}} d w_{L}^{*} \\
+\frac{\partial(H / L)_{L S}}{\partial H_{I}} d H_{I}+\frac{\partial(H / L)_{L S}}{\partial L_{I}} d L_{I} \\
d w_{L}^{*}=-f^{\prime \prime}\left((H / L)^{*}\right)(H / L)^{*} d\left(\frac{H}{L}\right)^{*}
\end{gathered}
$$

Since the equilibrium requires equality of the labour supply and demand, the comparative statics of the equilibrium requires: $d(H / L)^{*}=d(H / L)_{L s}=d(H / L)_{L D}$. The term $d w_{L}^{*}$ in (22) can be substituted with (23). After substitution of $d(H / L)^{*}$ with the demand relation (21) we arrive at: 


$$
\begin{aligned}
\left(1-\frac{\partial(H / L)_{L S}}{\partial \bar{a}} \frac{d \bar{a}}{d w_{L}} \mid f^{\prime \prime}\left(\left(H / L^{*}\right) \mid(H / L)^{*}\right) g^{\prime}\left(\omega^{*}\right) d \omega^{*}=\right. \\
\frac{\partial(H / L)_{L S}}{\partial \omega} d \omega^{*}+\frac{\partial(H / L)_{L S}}{\partial H_{I}} d H_{I}+\frac{\partial(H / L)_{L S}}{\partial L_{I}} d L_{I}
\end{aligned}
$$

which can be solved for $d \omega^{*}$ :

$$
d \omega^{*}=\frac{\frac{d L_{I}}{L_{I}+\int_{\bar{a}\left(w_{L} ; \bar{w}\right)}^{\left(\omega^{*}\right)}(1+a) f(a) d a^{2}}\left[\frac{d H_{I}}{d L_{I}}-\left(\frac{H}{L}\right)^{*}\right]}{\left(1-\frac{\partial(H / L)_{L S}}{\partial \bar{a}} \frac{d \bar{a}}{d w_{L}}\left|f^{\prime \prime}\left((H / L)^{*}\right)\right|(H / L)^{*}\right) g^{\prime}\left(\omega^{*}\right)-\frac{\partial(H / L)_{L S}}{\partial \omega}}>0 \text { if } \frac{d H_{I}}{d L_{I}} \geq\left(\frac{H}{L}\right)^{*}(25)
$$

With $\partial(H / L)_{L S} / \partial \bar{a}=0$ this yields the familiar comparative static result of the flexible wage case. 